\title{
Parábolas, altruismo espontáneo y coherencia cognitiva. Analizando la eficaz construcción de algunas parábolas
}

\section{Parables, Spontaneous Altruism and Cognitive Coherence. Analyzing the effective construction of some parables}

\author{
Teresa Bejarano Fernández" \\ Universidad de Sevilla. \\ Sevilla. España \\ tebefer@us.es \\ ID ORCID 0000-0002-0037-549
}

\begin{abstract}
Resumen: Varios recursos empleados en la construcción de un grupo de parábolas coinciden con puntos que la ciencia actual enfoca. 1) El hecho de que la situación ajena es percibida de un modo más objetivo, con menos sesgos, que la situación propia. 2) El "altruismo espontáneo", que empuja a conductas automáticas de ayuda. 3) La enorme influencia que el lenguaje puede ejercer para modular la atención, tanto la ajena como la propia. 4) La coherencia cognitiva, que interviene en el autocontrol, tanto el autocontrol moral como el que está al servicio de los propios intereses del sujeto. Al analizar el efecto de esos puntos en las parábolas en cuestión, intento mostrar que las capacidades comunicativas humanas están allí funcionando al máximo para facilitar la decisión del oyente, y que esa facilitación o ayuda es diferente por completo a las manipulaciones de cualquier tipo.
\end{abstract}

Palabras clave: parábolas; altruismo espontáneo; castigo altruista ; coherencia cognitiva; decisión moral.

\begin{abstract}
Several resources used in the construction of a group of parables coincide with points that current science focuses on. 1) The fact that the situation of others is perceived in a more objective way, with fewer biases, than one's own situation. 2) The "spontaneous altruism", which pushes towards automatic helpful behaviors. 3) The strong influence that language can have in modulating attention, both that of others and one's own. 4) Cognitive coherence, which intervenes in self-control, both moral self-control and that which is at the service of the subject's own interests. In analyzing the effect of these points on the parables at issue, I try to show that human communicative skills are there at their best to facilitate the hearer's decision, and that this facilitation process is completely different from manipulations of any kind.
\end{abstract}

Keywords: parables; spontaneous altruism; altruistic punishment; cognitive coherence; moral decision.

\footnotetext{
* Doy las gracias a los dos revisores anónimos porque su labor ha sido sumamente beneficiosa para este artículo.
} 


\section{INTRODUCCIÓN}

Este trabajo no pretende ayudar a leer un conjunto de parábolas. Esa tarea viene haciéndose desde hace muchos siglos, y yo soy incapaz de aportar ahí mejoras. Mi objetivo es más modesto y, sobre todo, muchísimo menos importante. Intentaré explicar por qué son tan eficientes esas parábolas. ¿Cómo intentan empujar a sus receptores hacia una decisión moral? Entre las muchas causas que sin duda habrá, yo detecto en su construcción varios puntos que están hoy muy presentes en teorías e investigaciones. Por supuesto, hace dos mil años nadie mencionaba ni analizaba esos puntos. Sin embargo, podían ya entonces ser usados - y a veces, de un modo magistral - para acrecentar la eficiencia comunicativa de un discurso.

¿Cuáles son esos puntos? En las secciones posteriores nos dedicaremos a analizar cada uno de ellos, y a intentar mostrar cómo intervienen - de una manera o de otra, en la primera parte o en el final- en la construcción de las parábolas. Aquí, en cambio, solo los mencionaré. 1) La representación de una situación ajena es más objetiva que la de la situación propia. Esto fue puesto de relieve en una controversia interna de la llamada "teoría de la mente". 2) El "altruismo espontáneo", que es un concepto que ha sido perfilado a partir de estudios experimentales en el niño y en los primates no humanos. Algunos autores quieren ver ya ahí el origen de la capacidad de decisión moral. Yo no participo en absoluto de esa opinión. Pero la eficiencia de algunas parábolas no habría sido posible si en sus primeros compases no activaran el altruismo espontáneo del receptor. 3) La "adicción humana a las narraciones", y, más en general, el poder del lenguaje para moldear a un nivel muy fino la atención del receptor. 4) La disposición a juzgar las acciones ajenas que no nos conciernen y a indignarnos o sentir admiración ante ellas. Este rasgo, si bien podría estar relacionado con el altruismo espontáneo, lo trataré por separado. Acerca de él se tiene claro hoy día que constituye una tendencia humana universal que en determinadas circunstancias (abajo intentaré precisar en cierta medida todo esto) se activa de modo automático. 5) La coherencia cognitiva, que es en último término a lo que esas parábolas apelan, ha sido (durante los últimos cuarenta años sobre todo) estudiada en sus muy variados usos y en su origen.

Las parábolas a las que se refiere el presente trabajo incluye, sin ánimo alguno de exhaustividad, la de Natán a David (2 Sam 12,1-15), el Buen Samaritano (Lc 10,25-37), y el Hijo Pródigo (Lc 15,11-32). Intentaré mostrar que en ellas se emplean estratégicamente todos esos puntos que hoy la investigación científica ha explicitado. Asimismo, en estrecha relación con lo anterior, voy a comparar dos tipos de decisión 
moral, aquella que se toma directamente ante las necesidades e intereses ajenos, y aquella otra que el receptor de esas parábolas es instado a tomar. A este respecto defenderé que la decisión moral ante las parábolas, aunque en el nivel cognitivo envuelve una dificultad mayor que el otro tipo, en el nivel moral mismo, en cambio, es facilitada por la estratégica y eficiente construcción de las parábolas. Pero también propondré que, a diferencia de lo que sucede en las manipulaciones de cualquier tipo, tal facilitación no significa en absoluto que la decisión resulte más atractiva o menos dura. Como se ve, el presente artículo no va a tratar sino de explicitar y detallar algo que todos hemos experimentado.

\subsection{Un paréntesis: la "teoría de la mente"}

La corriente de investigación llamada "teoría de la mente", mientras que no corresponde a ninguno de aquellos cinco puntos arriba mencionados, es sin embargo el área general en la que se ubica hoy el estudio de, al menos, tres de ellos. Por eso, daré aquí alguna referencia sobre esa corriente. Pero los lectores deben considerar este apartado como meramente optativo: La comprensión de las propuestas puede darse aunque se prescinda de él.

En 1978 — o sea, casi veinte años después del choque entre Chomsky y Skinner, y cuando el tabú contra el término "mente"y afines que había regido el estudio de los animales había perdido ya toda vigencia- se lanza la pregunta de si los chimpancés tendrán la capacidad de captar o inferir contenidos mentales ajenos. ${ }^{1} Y$, como una consecuencia inespera$\mathrm{da}$, se descubre pronto que los niños hasta los 4 años son incapaces de responder acertadamente en los tests de "falsa creencia". Se les muestra un video en el que un niño (Maxi) guarda su canica en un florero y se va; después, su madre mueve la canica a la caja de los juguetes, y se va. En ese momento, vuelve Maxi, y entonces el experimentador pregunta a los niños que han visto el video:" ¿Dónde irá Maxi a buscar su juguete?". Las respuestas de los niños menores de 4 años (a pesar de que se comprobó que ellos retenían bien la primera escena del video) no reflejan la falsa creencia que ha de tener Maxi (o sea, no reflejan el contenido mental ajeno), sino el conocimiento que ellos, los sujetos del test, tienen de la realidad. ${ }^{2}$ Durante los últimos años del siglo $X X$, a la vez que se refinaban

1 Cf. David Premarck - Guy Wooddruff, "Does the Chimpanzee Have a Theory of Mind?", Behavioral and Brain Sciences 1 (1978) 515-526.

2 Cf. Heinz Wimmer - Josef Perner, "Beliefs about Beliefs: Representation and Constraining Function of Wrong Beliefs in Young Children's Understanding of Deception", Cognition 13 (1993) 103-128. 
cada vez más los experimentos y se descartaban algunas explicaciones de tipo - digamos - periférico del fallo de los niños, surgieron varias controversias internas en los estudios de "la teoría de la mente", que es como más habitualmente se designa la captación de los estados y contenidos mentales ajenos. ${ }^{3}$

Entre esas controversias, hay que destacar la que se refiere al punto de vista de la primera persona, y tiene como su episodio inicial más notable la publicación conjunta en 1993 de dos artículos contrapuestos. ${ }^{4}$ Alvin Goldman, cercano a la fenomenología, defendió el carácter básico de las experiencias de primera persona y propuso que la simulación mental (un concepto con antiguas raíces en la historia de la filosofía) es el procedimiento que permite al sujeto predecir los estados mentales de otro individuo: "En la predicción de los estados mentales de otra persona, nosotros intentamos simular o reproducir el mismo estado, o secuencia de estados, en que esa persona está. Nos colocamos en su posición, en su pellejo, y vemos qué es lo que nosotros llegaríamos entonces a creer, sentir o hacer." Alison Gopnik, en cambio, aprovechando el énfasis que los nuevos estudios habían puesto en la tarea de captar los estados mentales ajenos, propuso derivar de tal tarea el conocimiento de la mente propia de uno mismo, y combatir así el punto de vista de la primera persona, y la fenomenología en general. Esa idea conectaba en último término con el conductismo filosófico (y más particularmente, con Wilfrid Sellars y su "mito de Jones"5). Pero Gopnik la desarrolló de un modo nuevo: El niño, como un científico, iría infiriendo las reglas de la"teoría de la mente" hasta llegar a obtener una "teoría — general, o sea, tanto para los demás como para él mismo- de la teoría de la mente". O, en las propias palabras de Gopnik: "Nuestra comprensión de la mente envuelve, al menos en gran parte, el aprendizaje de estructuras causales abstractas, que se lleva a cabo a partir de la evidencia — principalmente de la evidencia de las conductas

3 A la"teoría de la mente" - Theory-of-Mind, o ToM- se la conoce también por otros nombres, como "mind-reading", "mentalizing", o "meta-representacional capacity". Sin embargo, el de "teoría de la mente", que ha sido usado por autores con posturas muy diferentes, es el más consolidado.

4 Alvin Goldman, "The Psychology of Folk Psychology", Behavioral and Brain Science 16 (1993) 15-28; y Alison GopNIK, "How We Know Our Minds: The Illusion of FirstPerson Knowledge of Intentionality", Behavioral and Brain Sciences 16 (1993) 1-15 y 90-101.

5 Cf. Wilfrid Sellars, "Empiricism and the Philosophy of Mind", in Herbert Feigl - Michael Scriven (eds.), Minnesota Studies in the Philosophy of Science. Volume I: The Foundations of Science and the Concepts of Psychology and Psychoanalysis Minnesota, University of Minnesota Press, 1956. Edición española en Ciencia, percepción y realidad, Madrid, Tecnos, 1971. 
observadas: De aquí la analogía entre el aprendizaje que llevan a cabo los niños y el cambio de teoría en la ciencia".

Poco después, en 1996, se descubrieron en el cerebro de los macacos las "neuronas de espejo" (unas neuronas que se activaban exactamente del mismo modo cuando el macaco veía a alguien agarrando algún objeto y cuando él mismo, el macaco, agarraba el objeto, y que incluso diferenciaban con toda precisión si se estaba agarrando con los dedos un objeto pequeño, o por el contrario, se usaba la mano entera para coger un objeto grande), y Goldman y los demás defensores de la simulación celebraron en seguida triunfalmente tal descubrimiento. ${ }^{6}$ Pero "la primacía de la lectura de la mente ajena" (o sea, el núcleo de la postura de Gopnik) reaparece más tarde en una versión muy diferente, la de Peter Carruthers. ${ }^{7}$ Este autor también niega que haya introspección alguna para las actitudes proposicionales ("Our knowledge of our own attitudes results from turning our mindreading capacities upon ourselves"), pero defiende una propuesta basada en una modularidad extrema (donde los módulos mentales son innatos y están en principio completamente desconectados unos de otros). De ese modo explica los qualia de la fenomenología como consecuencia del lenguaje (del lenguaje social y aprendido, no del supuesto"lenguaje del pensamiento"de Fodor), el cual lograría acabar con el aislamiento y la desconexión inicial de las sensaciones. Tras tal explicación, Carruthers ha de proponer, claro está, que los animales no sienten realmente sus percepciones, aunque saquen de ellas las consecuencias conductuales adecuadas. Pero en respuesta a Bernard Baars, que recurre al ejemplo del dolor para sostener que ahí "accurate self-knowledge is firmly established", Carruthers matiza su postura quitándole algo de su rotundidad y claridad inicial. ${ }^{8}$ Intentemos resumir la línea general de toda esta sucesión de episodios.

A mi juicio, esta primera controversia debe llevar a los futuros investigadores a estudiar cada vez más cuidadosamente y con todos los tipos de recursos disponibles la diferencia entre, por un lado, el percibir o creer incluso de modo pleno, o sea, con riqueza de matices tanto informativos como también de experiencia y afectivos, y, por otro lado, el pensar (como en los llamados "estados de segundo orden" o "metarrepresentaciones") que uno mismo está percibiendo o creyendo algo. Es, por ejemplo, muy

6 Cf. por ejemplo, Vittorio Gallese - Alvin Goldman, "Mirror Neurons and the Simulation Theory of Mind-reading", Trends in Cognitive Sciences 2 (1998) 493-501.

7 Cf. Peter Carruthers, "How We Know Our Own Minds: The Relationship Between Mindreading and Metacognition", Behavioral and brain sciences 32 (2009) 1-62.

8 Bernard BAARS, "Is Feeling Pain Just Mindreading? Our Mind-brain Constructs Realistic Knowledge of Ourselves", Behavioral and brain sciences 32 (2009) 19-20. 
verosímil que los conceptos "creer"o "percibir" aparecieran en un principio solo y exclusivamente para hablar acerca de la creencia de otra persona o acerca del pasado propio de uno mismo ( para decir, por ejemplo, "Él cree que su madre está aquí" o"Entonces vi el manantial").

Otra discusión es la que versa sobre la importancia que en la captación de la mente tienen, ya el cuerpo, ya el lenguaje y la cultura. El papel del cuerpo era muy destacado por el simulacionismo de Goldman, pero también por Gopnik y su propuesta de que el aprendiz de"la teoría de la teoría" ha de partir de la observación de las conductas y pautas motoras ajenas (algunas de las cuales, según ella, serían imitadas automáticamente ya por los niños recién nacidos ${ }^{9}$ ). Respecto al papel del lenguaje (cuya importancia ya vimos subrayada de modo extremo por Carruthers), hay que señalar que es Daniel Hutto quien dio un papel protagonista a la propuesta de que es concretamente la recepción de narraciones la que instaura en el niño la "teoría de la mente".${ }^{10}$ Esta idea, a la que en relación

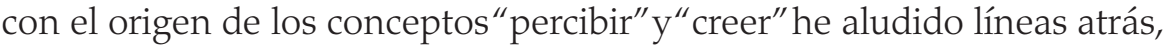
encaja bien con ese indiscutible "universal humano" que el gusto por las narraciones, ficticias o no ficticias, supone. Una propuesta nueva, aunque emparentada con la anterior, es el constructivismo radical de Marco Fenici y Tadeusz Wieslaw Zawidzki:"Mental states are constituted by our cultural practices of attributing them. (...) Mindreading and mindshaping are entirely co-dependent." ${ }^{11}$ Este último artículo se preocupa también de asignar a esas prácticas culturales unas ventajas adaptativas que consistirían en expresar compromisos con planes conjuntos y apuntalar así el estilo de vida cooperativo que tuvieron que adoptar los humanos.

Sin embargo, yo subrayaría como de importancia máxima el estudio acerca de los llamados dos modos, el primitivo y el avanzado, de la teoría de la mente. De hecho (quizá el lector lo habrá notado) estoy convencida

9 El asumir esa propuesta de la imitación automática por los bebés recién nacidos era —nótese - un paso obligado para Gopnik, o, más concretamente, para su objetivo de rechazar la tesis simulacionista de que los movimientos ajenos se comprenden e interpretan a partir del conocimiento de los movimientos parecidos de uno mismo. Conviene añadir que hoy día, gracias sobre todo a las múltiples investigaciones de un extenso grupo ligado a Thomas Suddendorf, esa presunta imitación de los recién nacidos se considera cada vez más infundada. Recordemos además que las neuronas de espejo de los primates tienen que ver con movimientos (los de la mano) cuya visibilidad en el propio cuerpo cuerpo -única entre todos los animales- ofrece un inicio ideal para llegar a comprender los movimientos ajenos.

10 Cf. Daniel Hutro, "Folk Psychology as Narrative Practice", Journal of Consciousness Studies 16 (2009) 9-39.

11 Marco FenICI - Tadeusz Wieslaw ZAWIDZKI, "The Origins of Mindreading: How Interpretive Socio-cognitive Practices Get Off the Ground", Synthese (2020): https:// doi.org/10.1007/s11229-020-02577-4. 
de que ese estudio será útil en las dos controversias anteriores. Además, y mucho más importante, creo que es atendiendo a la diferencia entre los dos modos como habría que dilucidar el posible vínculo entre la "teoría de la mente" y la peculiaridad mental únicamente humana. Pero la distinción entre el modo primitivo y el modo avanzado se ha enturbiado desde el 2005. Antes de esa fecha, en cambio, ambos se describían sin grandes problemas. Por un lado, la estimación de lo que otro individuo puede ver o no ver es una capacidad indiscutiblemente poseída por los niños de bastante menos de cuatro años y por los chimpancés, y así se identificaba esa capacidad con el modo primitivo de la teoría de la mente. ${ }^{12}$ Por otro lado, el éxito en los tests de falsa creencia se identificaba con el modo avanzado. Pero después, con el diseño de tests de falsa creencia no verbales, se ha venido proponiendo que, no solo los niños a la edad de 2 años (o, como se diría más tarde, de 18 o 15 meses), sino también los chimpancés, comprenden la creencia falsa de otro individuo. ${ }^{13}$ ¿Habrá entonces que renunciar a la existencia de dos modos de la teoría de la mente que sean intrínseca y cualitativamente distintos uno de otro? ¿O conviene más bien redescribir el modo primitivo? Hay lógicamente estudiosos que se muestran reacios a aceptar aquellos nuevos datos. Pero ese negacionismo resulta cada vez más difícil de sostener (sobre todo porque también los adultos humanos mostramos en ciertos momentos rasgos del nuevo modo primitivo). Los principales autores que se han esforzado en redescribir el modo primitivo son IanApperly Stephen Butterfill, Michael Tomasello, Victoria Southgate, y Bence Nanay. ${ }^{14}$ Pero mis preferencias van por una hipótesis - por una redescripción del modo primitivo- un poco distinta a las que acabo de mencionar. Esa hipótesis

12 Cf. Michael Tomasello - Josep Call - Brian Hare, "Chimpanzees Understand Psychological States - the Question is Which Ones and to What Extent", Trends in Cognitive Sciences 7 (2003) 153-156.

13 Cf. Kristine Onishi - Renée Baillargeon, "Do 15-Month-Old Infants Understand False Beliefs?", Science 308 (2005) 255-258; Christopher KrupenYe - Kano FumiHIRO Satoshi Hirata - Josep CAll - Michael Tomasello, "Great Apes Anticipate that Other Individuals Will Act according to False Beliefs", Science 354 (2016) 110-114; Kano Fuminiro - Christopher KRUPENYE - Satoshi Hirata - Masaki TomonagA - Josep Call, "Great Apes Use Self-experience to Anticipate an Agent's Action in a False-belief Test", Proceedings of the National Academy of Sciences 116 (2019).

14 Cf. Ian Apperly - Stephen Butterfill, "Do Humans Have Two Systems to Track Beliefs and Belief-Like States?", Psychological Review 116 (2009) 953-970. Michael Tomasello,"How Children Come to Understand False Beliefs: A Shared Intentionality Account", Proceedings of the National Academy of Sciences 115 (2018) 8491-8498; Victoria Southgate, "Are Infants Altercentric? The Other and the Self in Early Social Cognition", Psychological Review 127 (2020) 505-523; y Bence NanAY, "Vicarious Representation: A New Theory of Social Cognition", Cognition 205 (2020) 104-451. 
me permite proponer y defender con, al menos algunos argumentos, la asociación entre el modo primitivo y el altruismo espontáneo y no demandante, y entre el modo avanzado y la capacidad moral máximamente demandante. ${ }^{15}$

¿Se me pide escoger una característica general de los estudios de la "teoría de la mente"? Yo subrayaría que, con ellos, la psicología experimental está dedicando algunos de sus esfuerzos a estudiar qué es a la vez exclusivamente humano y universalmente humano. Quizá eso podría hacer estos estudios muy interesantes para la Antropología Filosófica y para la Filosofía en el sentido más clásico.

\section{UN PUNTO QUE LOS SIMULACIONISTAS INVOCARON EN SU CONTROVERSIA CON LOS PARTIDARIOS DE LA “TEORÍA DE TEORÍA"}

En los primeros años 90 había una fuerte discusión entre dos posturas que pertenecían ambas al área de "la teoría (o captación) de la mente ajena". Una de ellas, el llamado"simulacionismo", sostenía que el sujeto simula estar -él, el sujeto- en las circunstancias del otro individuo, y que basta esa simulación —ese ponerse en el pellejo del otro individuopara que fluyan sin más los pensamientos que son adecuados a aquellas circunstancias. La otra, llamada "teoría de la teoría", defendía sin embargo que el sujeto aplica unas ciertas reglas para comprender tanto las mentes de los otros como su propia mente.

En un momento dado de esa discusión, los partidarios de la "teoría de la teoría" realizaron experimentos que mostraron que en la atribución a otro individuo no estaban incluidos muchos sesgos que desde hacía tiempo se sabía que afectan a la conducta humana. Por ejemplo, todos tenemos la experiencia de que cuando perdemos, por ejemplo, un tren por solo un minuto, nos disgustamos y enfadamos más que cuando lo perdemos por una hora. Sin embargo, los resultados de aquellos experimentos indicaban que ese - claramente irracional- plus de enfado no se atribuía, o se atribuía en mucha menor medida, al individuo cuyos pensamientos el sujeto tenía que inferir. De ahí se concluye —afirmaban los autores de esos estudios- que el simulacionismo no es realmente el procedimiento seguido en las tareas de atribución. ${ }^{16}$

15 Cf. Teresa Bejarano, "The Most Demanding Moral Capacity: Could its Base Evolutionarily Arise?" (submitted).

16 Este pequeño episodio dentro de la controversia entre las dos posturas es descrito años después por Rebecca SAXE, "Against simulation: the argument from error", Trends in Cognitive Sciences 9 (2005) 174-179. 
Pero entonces los simulacionistas propusieron una matización. Citemos a Jane Heal, quien fue la primera que sostuvo que aquella diferencia mostrada en los resultados experimentales no minaba el simulacionismo. Tal diferencia, explicaba Heal, se debe solo a que en las escenas que están lejos de la situación propia de uno, las cosas se pueden ver con más objetividad y claridad. ${ }^{17}$ Este hecho que Heal invoca es lo que nos interesa.

\section{LA COMPARACIÓN DE SITUACIONES, UNA AJENA Y OTRA PROPIA, EN ALGUNAS PARÁBOLAS}

Tal hecho había sido utilizado desde milenios atrás. Más en concreto, fue puesto en práctica en la construcción de un conjunto de parábolas bíblicas. Como ejemplo inicial, detengámonos en la que emplea Natán ante David (2 Sam 12,1-7).

Ahí la comparación de las dos situaciones está —ése es el motivo de que la haya escogido como primer ejemplo- particularmente desplegada. Esa particularidad probablemente tiene que ver, primero, con el hecho de que esa parábola es la más antigua —el modelo textual, podríamos decir - del que será nuestro conjunto, y, segundo y más importante, con que es la única que se dirige a un destinatario particular cuya historia nos ha sido contada en el mismo libro páginas atrás.

Donde esta parábola sí que coincide con las demás del conjunto es que, en todas ellas, la diferencia entre la representación de la situación propia y la de la situación ajena (o sea, el hecho invocado por Jane Heal) juega un papel clave. Pero no podemos pasar de inmediato a estudiar ese recurso. Hay que dedicar previamente unas líneas a un asunto más general.

\section{4. ¿POR QUÉ UNA SITUACIÓN NARRADA ES AHÍ MÁS EFICAZ QUE UNA SITUACIÓN PERCIBIDA?}

Prestemos pues atención al hecho obvio de que las parábolas son narraciones lingüísticas, y preguntémonos si la observación de una situación real podría sustituir sin merma de eficacia a la primera parte de ese tipo de parábolas. Es verdad que, a veces, basta con que una escena que no

17 Cf. Jane HeAL, "Simulation and cognitive penetrability", Mind and language 11 (1996), 44-67. Justo en la misma línea, Timothy SHort, - Kevin RigGs, “Defending Simulation Theory against the argument from error", Mind and language 31 (2016) 248-262: "The relevant biases are not triggered in the subject or used as part of the simulation because the subject is not actually in the other individual's situation with its affective import". 
nos concierne sea visible desde nuestra posición para que pueda activar nuestro altruismo espontáneo. Pero eso solo sucederá —insisto- raras veces, pues el que realmente miremos y atendamos específicamente a una tal escena no tendrá lugar a menos que en ese momento estemos inactivos y sin meta alguna activada; a menos que estemos, en definitiva, dispuestos a la actitud de espectador curioso. Aparte de eso, ante una escena en la que intervienen varios individuos desconocidos y de la que desconocemos el contexto, no tiene necesariamente que estar claro con cuál de esos individuos nos identificaremos, a cuál simularemos. Así, bastante a menudo, los individuos cuando observan el maltrato de un desconocido por parte de otro desconocido no llegan realmente a enfadarse a menos que la empatía sea manipulada de antemano. Dicho de otra forma, el llamado"castigo altruista" —o sea, el castigo que una tercera persona no relacionada con la víctima inflige al autor de un maltratoes mucho menos común de lo que en un primer momento ( $\mathrm{y}$ a la vista de los resultados obtenidos en experimentos basados en juegos, como el del Dictador, por ejemplo) se llegó a creer. ${ }^{18}$ En resumen, las reacciones del altruismo espontáneo ante una escena observada solo se producirán si logran superar varios obstáculos de diferentes tipos.

Eso no sucede, en cambio, ante la narración. Está claro que un mensaje lingüístico que nos están dirigiendo es más difícil de desatender que aquel tipo de escena. Ante ese mensaje, la atención por parte del receptor no requiere ya en absoluto que éste estuviera de antemano desocupado y dispuesto a la actitud de espectador.

Pero, más allá de eso y más profundamente, está el hecho de que el lenguaje, aún siendo tan pobre en relación con la percepción, es sin embargo capaz de moldear de un modo muy preciso cuáles son los aspectos a los que el receptor debe prestar atención. ${ }^{19}$ Esa capacidad puede volverse portentosa en los usos artísticos o particularmente creativos del lenguaje, pero lo importante es que no deja de estar presente en ninguna conversación ordinaria. Por supuesto, ahí intervendrá la elección entre

18 Esa rectificación se la debemos a C. Daniel BATson et al., "Anger at Unfairness: Is it moral outrage?", European Journal of Social Psychology, 37 (2007) 1272-1285, o a Eric J. Pedersen - William H. B. McAuliffe - Michael E. Mccullough, “The Unresponsive Avenger: More evidence that disinterested third parties do not punish altruistically", Journal of Experimental Psychology: General 147 (2018) 514-544.

19 En realidad, el origen de esa capacidad está en el origen de la comunicación peculiarmente humana, o sea, en el gesto de apuntar. Ahí ya hay, por más tosca que sea, una modulación de la atención del receptor. Pero ahora sólo nos interesa atender al lenguaje. 
las muchas posibles maneras (recordemos el Sinn de Frege) ${ }^{20}$ de designar una misma referencia; pero, más allá del nivel léxico, habrá también muchas elecciones de tipo gramatical (del tipo "A después de B" frente a"B antes de $\mathrm{A}^{\prime \prime}$, o voz pasiva frente a activa) y muchísimas más, que tienen lugar en todos los otros niveles envueltos en una comunicación lingüística. Véase, por ejemplo, cómo la narración de Natán busca subrayar la interioridad del hombre pobre, señalando primero sus acciones respecto a su oveja, e indicando después explícitamente el cariño que le tenía. ${ }^{21}$ En definitiva, podemos dar por sentado que la primera parte de una buena parábola - al modular, o moldear muy finamente, como cualquier buen texto, la atención del receptor- sabe despertar en él aquellas reacciones que su productor deseaba despertar.

\section{LAS DOS PARTES DE ESE TIPO DE PARÁBOLAS Y LA APELACIÓN A LA COHERENCIA COGNITIVA}

En la primera parte de la parábola de Natán no había nada que se opusiera a ese deseo del profeta. La situación ahí descrita no envolvía en absoluto a su destinatario, y, por tanto (como decía Heal) los sesgos que, de haber estado él envuelto, le habrían podido afectar, no le han afectado en absoluto. Así, lo que Natán le ha narrado lleva a David a responder con la fuerte reprobación e indignación que eran adecuadas, y asimismo con las amenazas que su status regio en ese momento y su temperamento de guerrero hacían previsibles. Esas reacciones - tanto las emociones que le embargan como igualmente el juicio moral que él emite-son espontáneas y no han requerido esfuerzo subjetivo alguno.

20 Cf. Gottlob Frege, "Über Sinn und Bedeutung”, Zeitschrift für Philosophie und philosophische Kritik 100 (1892) 25-50. Traducción española: IDEM, Ensayos de semántica y filosofía de la lógica, Madrid, Tecnos, 1998.

21 André Wenin, “David et l'histoire de Natan (2 Samuel 12,1-7), ou: le lecteur et la fiction prophétique du récit biblique", en Daniel MARGUERAT (ed.), La Bible en récits. L'exégèse biblique à l'heure du lecteur, Genève, Labor et fides, 2003, 160: "En qualifiant la brebis de «petite» et en précisant que le pauvre a dû l'acheter —à l'inverse du riche qui possède ses biens comme par nature-, Natan souligne déjà discrètement un investissement particulier de l'homme envers son unique bête. La suite va dans la même direction, mais en crescendo. Natan s'y emploie à décrire avec force de détails comment cette agnelle en vient à être traitée comme une fille. Une véritable intimité se noue entre l'homme et cette brebis qu'il a fait vivre pour que, avec lui et ses fils, elle grandisse, mangeant de sa nourriture, buvant à sa coupe et dormant sur son sein. Tous ces détails ont pour effet de charger d'une forte émotion la description de ce pauvre qui, démuni de tout, semble vouloir compenser son manqué d'avoir par un surplus d'investissement relationnel et affectif, qui confère à son agnelle une valeur inestimable, sans aucune commune mesure avec sa valeur marchande." 
En cambio, cuando se pasa a la segunda parte de este tipo de parábolas —al“ ¡Tú eres ese hombre!” (2 Sam 12,7) con que Natán acusa a David, o al "Haz tú lo mismo" (Lc 10,37) con el que acaba la parábola del Buen Samaritano-, entonces ya sí que surgen las protestas y los"peros" en el interior del receptor. David tendría la tentación de replicar que su caso no era equiparable al del hombre rico de la narración: "Yo era rey, y además, por eso, tenía la obligación de defender mi prestigio". Y nosotros, que ante la narración del samaritano y el herido, nos habíamos llenado de compasión y admiración, también querríamos buscar un escape cuando oímos que se nos interpela: "Es estupendo lo que hizo el samaritano, pero yo me debo a mis compromisos profesionales, y no puedo perder el tiempo.Yo, con preocuparme de quienes me son más cercanos, ya tengo más que de sobra". Eso, y mucho más de ese tenor, es lo que los receptores querrán argüir. Pero, a pesar de todo, a cada receptor su propia capacidad para la coherencia cognitiva le insta a aceptar la semejanza entre las dos situaciones.

La apelación a la coherencia cognitiva es lo que en último término aportan estas parábolas. La decisión moral del receptor ante esas parábolas estriba en obedecer a la coherencia cognitiva, y reconocer así la semejanza entre la situación narrada y la propia de uno. Esa es, desde luego, una decisión moral, pero de un tipo diferente al de aquellas decisiones morales que tomamos directamente ante los intereses y necesidades que captamos en otros. Tenemos que concretar qué es lo que esos dos tipos tienen en común, y también qué es lo que distingue a uno de otro.

\section{UNA OBLIGADA DIGRESIÓN: BUSCANDO CARACTERIZAR, AUNQUE SEA DE MODO SOMERO E INCOMPLETO, QUÉ ENTIENDO POR DECISIÓN MORAL}

Para intentar comparar esos dos tipos de decisiones morales, conviene que antes aclare qué estoy entendiendo por una decisión moral. Ya arriba dije que el juzgar moralmente las acciones ajenas que no nos conciernen $-\mathrm{O}$ sea, el sentir indignación cuando se ve una maldad, o admiración cuando se ha asistido a una buena acción- no requeriría decisión moral alguna. Ahora añadiré que el ayudar a alguien de modo automático —el lanzarse a la conducta de ayuda sin que ello nos exija un esfuerzo duro y penosono sería tampoco una decisión moral, no sería un acto realmente libre, por más que pueda ser una conducta útil para el receptor de la ayuda.

Este último asunto está bajo los focos desde hace unos pocos años. Más concretamente, lo está desde que se empezó a estudiar el altruismo que es observable en los niños muy pequeños y quizá también en los 
chimpancés o los grandes monos en general, o sea, el que hoy viene llamándose altruismo espontáneo. Tomasello lo caracterizó en el título de un artículo: "Why Be Nice? Better Not Think About It". ${ }^{22}$

Ese altruismo ha sido a veces propuesto como el origen de la moral humana en la evolución. ${ }^{23}$ Yo, sin embargo, he propuesto que esos dos rasgos son sostenidos por dos bases distintas, que serían respectivamente el modo primitivo y el modo avanzado de la teoría de la mente. ${ }^{24}$ Pero, más allá de la hipótesis acerca de las respectivas bases, hay datos que sugieren que el altruismo espontáneo y la decisión realmente moral no se pueden considerar etapas en el desarrollo de una misma capacidad. El altruismo espontáneo aparece en el niño muchísimo antes, no ya de las decisiones altruistas realmente costosas (o sea las que yo llamo genuinamente morales), sino incluso del tipo más simple de autocontrol no moral (el autocontrol que lleva, por ejemplo, a preferir, entre dos golosinas, la que es mejor pero un poco más tardía).

En definitiva, yo formularía mi postura del modo siguiente: Las decisiones morales, a diferencia de las reacciones del altruismo espontáneo, tendrían lugar cuando el sujeto capta intereses y necesidades de otro individuo que chocan con alguna motivación que él, el sujeto, tenga entonces fuertemente activada. Por supuesto, con esta digresión no he mostrado nada - me apresuro de nuevo a reconocerlo - ni he dado argumento alguno: Todo se ha reducido a desplegar y explicitar la postura que ya de antemano yo había adoptado. Pero, al menos, podemos ahora seguir con la cuestión que arriba se planteó.

\section{LA MAYOR DIFICULTAD COGNITIVA DE LA DECISIÓN MORAL QUE TIENE LUGAR ANTE LAS PARÁBOLAS}

Comparemos ya los dos tipos de decisión moral. ¿Cuál es el más difícil de los dos tipos? Eso depende, claro, de cuál sea el sentido de dificultad que enfoquemos. Así pues, veremos, primero, la dificultad cognitiva, y después, la propiamente moral.

22 Michael Tomasello, "Why Be Nice? Better Not Think About It", Trends in Cognitive Science 16 (2012) 580-581. Algún tipo de altruismo sería también atribuible con pleno fundamento a los Neandertales: Algunos de los ejemplares adultos conservados presentan señales inequívocas de haber sobrevivido años a lesiones o enfermedades que los incapacitaban por completo para conseguir alimento. Cf. Penny SPIKINS et al., "Living to Fight Another Day: The Ecological and Evolutionary Significance of Neanderthal Healthcare", Quaternary Science Reviews 217 (2019) 98-118.

23 Cf. Frans de WAAL, The Age of Empathy: Nature's lessons for a kinder society, New York, Three Rivers Press, 2009; y SPIKINS et al.,"Living to Fight Another Day”, 98-118.

24 Cf. Bejarano, “The Most demanding Moral Capacity” (submitted). 
En la decisión ante las parábolas, hay una mayor dificultad cognitiva que en las decisiones morales primarias. Allí hay al principio una narración que hay que comprender, y que tendrá que ser comparada después con una situación del tipo de las que suscitan las decisiones morales de tipo primario, de modo que al final se pueda activar la coherencia cognitiva del sujeto. En resumen, este tipo —el no primario- de decisiones le añade a la dificultad cognitiva propia del otro tipo tres nuevas fuentes de dificultad: en primer lugar, la comprensión lingüística de la narración (que es sin duda mucho más difícil que la comprensión de una petición o una llamada, las cuales son formas de habla que podrían darse sin necesidad de sintaxis, ni de desplazamiento respecto al aquí y ahora), en segundo lugar, la comparación entre las dos estructuras, o, dicho de otro modo, las dos situaciones que el sujeto tiene que analizar, $\mathrm{y}$, finalmente, la activación de la coherencia cognitiva.

La dificultad de la narración no es relevante salvo que quisiéramos enfocar los primeros tiempos del Sapiens. La comparación de estructuras, en cambio, sí debe ser tenida en cuenta. Esa es una tarea que ha sido muy estudiada por los autores que investigan la resolución de problemas, ${ }^{25}$ la creatividad literaria (véase el blending de Turner) ${ }^{26} \mathrm{o}$ el aprendizaje por los niños del pensamiento relacional (Christie \& Gentner). ${ }^{27}$ En cualquier caso, está claro que esa comparación es demandante desde el punto de vista cognitivo. Ahí, pues, reside muy probablemente una importante fuente del plus de dificultad que presentan las"decisiones morales ante parábolas" sobre las"decisiones morales primarias".

Respecto a la coherencia cognitiva, podemos decir que, como tendencia al menos, está indudablemente presente en los seres humanos. ¿En qué consiste? Empecemos por señalar que la tendencia a tratar de modo similar los objetos similares se cumple en la conducta animal: es un rasgo claramente adaptativo. Después, cuando el ser humano llega a ser capaz de comparar relaciones, aquella tendencia puede"reusarse" en el nivel de relaciones, y no ya de objetos, y de ahí procede lo que estamos llamando coherencia cognitiva. ${ }^{28}$

25 Cf. Mary L. Gick - Keith J. HolYOAK, "Schema induction and analogical transfer", Cognitive Psychology 15 (1983) 1-38.

26 Cf. Gilles Fauconnier - Mark Turner, "Rethinking Metaphor", in Ray W. GibBs (ed.), The Cambridge Handbook of Metaphor and Thought, Cambrigge, Cambridge University Press, 2008, 53-66.

27 Cf. Stella CHristie - Dedre Gentner, “Where Hypotheses Come From: Learning New Relations by Structural Alignment", Journal of Cognition and Development 11 (2010) 356-373: https://doi.org/10.1080/15248371003700015.

28 Como uno de los revisores advierte, la verdad es que "coherencia cognitiva" es un término poco adecuado, que no conecta con la base real del fenómeno. ¿Qué podemos 
Esta capacidad puede intervenir en tareas de autocontrol complejo, de un autocontrol que no tiene por qué ser necesariamente moral. Así es explicado por Schwartz de un modo muy pedagógico con el siguiente ejemplo:

Ralph reasons to himself: "If I don't floss tonight, I won't lose my teeth or damage my gums as a result of just this one non-flossing. Flossing or not flossing tonight can make no discernible difference to my dental health". So Ralph neglects to floss and proceeds happily off to bed. (...) What Ralph thinks is correct. Nevertheless, we should seek for some way to undermine these claims. (...) You are making a non-justified exception. This is a violation of the principle of equality, which is a basic and fundamental principle of rationality. "Treat like things like". ${ }^{29}$

O sea, si yo aplico una "amnistía" al día de hoy, ¿por qué no voy a aplicarla también a cada día, si todos los días son iguales en relación con aquella de mis metas que está en juego aquí? O, a la inversa, si yo creo que para los demás días será necesario el cepillado de dientes, ¿por qué no lo juzgo así para el día de hoy? La semejanza que aquí se invoca es la que hay entre mi situación de hoy y mi situación de otros días.

En las tareas de autocontrol complejo, se cumplen dos"leyes psicológicas" que tienen ambas que ver con el tiempo, y que probablemente están en cierto modo relacionadas una con otra. ${ }^{30}$ En los casos en que el autocontrol nos urge hacia una conducta fastidiosa para alcanzar una meta lejana en el tiempo, esa meta (por ejemplo, la de conservar la dentadura cuando avancemos en edad) tiende a devaluarse tanto más cuanto más alejado en el futuro se prevea su disfrute. Los casos, en cambio, en los que el autocontrol exige inhibición influyen sobre la "duración

decir de esa base? La retención de unos episodios — su retención en la memoria a corto plazo - es necesaria, claro está, pero no basta a menos que vaya acompañada de la capacidad de comprenderlos todos conjuntamente (¿equivale esa capacidad a lo que se viene llamando "memoria de trabajo"?). Para decirlo de otro modo, unas premisas no son en realidad premisas hasta que no se las moviliza hacia una conclusión. Seguramente el origen de esta capacidad humana tiene que ver con la recepción del mensaje de varias palabras. (En el inicio mismo, antes de que se creara el"pegamento" gramatical, habría ayudado ahí la pauta entonatoria única en la que se ensartan las palabras). Conviene además aclarar aquí —como en otras partes de este artículo también lo he hecho- que el calificativo de cognitiva debe entenderse en un sentido amplio, para que incluya lo informativo, lo experiencial y las emociones.

29 Stephen Schwartz, "Soritic thinking, vagueness, and weakness of will", New Ideas in Psychology 27 (2008) 18-31: https://doi.org/10.1016/j.newideapsych.2007.12.001.

30 Se las llama habitualmente "leyes", porque, especialmente la primera, han sido elaboradas matemáticamente. 
subjetiva", de modo que la duración del tiempo de espera nos parecerá tanto mayor cuanto mayor sea nuestra motivación hacia la meta. ${ }^{31}$

En otras ocasiones, en cambio, la semejanza que se invoca en el autocontrol complejo no es la que hay entre distintos puntos temporales, sino entre una situación que me es narrada y una situación que me envuelve a mí. Tal semejanza puede usarse igualmente —igual que en el ejemplo del cepillado de dientes - para muchos fines que no tienen que ver con la moral. Pero en algunas ocasiones, su uso estará encaminado hacia una decisión moral. Así es como la tendencia a la coherencia cognitiva puede acabar jugando un papel clave en la construcción de un tipo de parábolas bíblicas, aun cuando en sí misma esa tendencia — repitono tenga por qué estar ligada a la moral.

Pero aquí aparece un problema. La coherencia cognitiva obedece a la verdad —al hecho de una semejanza-, y yo acepto que el núcleo de la decisión moral es la obediencia a la verdad. ¿Por qué entonces la coherencia cognitiva puede a veces estar desligada de la moral? ¿Por qué puede respaldar cualquier meta del sujeto, incluso si es un capricho banal o incluso si es nuclearmente injusta? ${ }^{32}$ Está claro que, para replicar a esa objeción, tenemos que diferenciar el tipo de verdad que es respetado en cualquier tipo de coherencia cognitiva y el tipo de verdad que es respetado en la decisión moral. Las decisiones morales, al menos en su mayoría ( ¿o sería mejor decir que al menos en su última instancia?), se asientan sobre la captación de los intereses del otro. Por tanto, es la semejanza esencial entre uno mismo y el otro —esa muy especial

31 Este párrafo sobre las dos"leyes"responde a la recomendación de un revisor anónimo que me sugería tener en cuenta los estudios sobre la conciencia del tiempo. Pero, como en esa recomendación yo veo que se me brinda una atractiva apertura hacia horizontes más amplios, voy a añadir algo más. Ciertamente debemos admirarnos de la capacidad humana de pensar el pasado (ya el que recordamos personalmente, ya el de las narraciones familiares o históricas o científicas que nos han transmitido) y de pensar también futuros más o menos lejanos. El viaje mental en el tiempo es un universal humano que es constantemente ejercido. Sin embargo, nuestra conciencia del tiempo está quizá, como otros varios rasgos humanos, conformada por nuestra condición de hijos de Poros y Penia. Nótese que, aunque somos capaces de viajar mentalmente a través de los milenios, estamos siempre atados a un solo punto en el tiempo, y ello no solo cuando estamos afanándonos en nuestro aquí y ahora, sino también en esos vuelos de nuestra imaginación. En otras palabras, acerca de la posibilidad de vivir simultáneamente en todos los puntos del tiempo, solo captamos que es imposible para nosotros.

32 Esta pregunta, huelga decirlo, es diferente de la que nos hacíamos arriba. Allí comparábamos la decisión moral primaria y la decisión moral ante las parábolas. Ahora, en cambio, estamos comparando la coherencia cognitiva a la que se apela en las parábolas y la coherencia cognitiva que es usada en tareas de autocontrol no moral. 
semejanza - la que tiene que ser obedecida en las decisiones morales, sean primarias o no primarias. En cambio, para el autocontrol no moral que se necesitaría, por ejemplo, en el caso descrito por Schwartz, la coherencia cognitiva nunca se aplica a esa especial semejanza, sino a otras que son muy distintas de esa. En otras palabras, lo que en este contraste estaría en juego es que la fuerza de voluntad no tiene que identificarse necesariamente con las decisiones morales, sino que opera en un campo mucho más amplio. Precisamente fue en sus modalidades no morales (y adaptativamente ventajosas) donde, casi con toda probabilidad, el autocontrol complejo surgiría originariamente en la evolución.

De cualquier modo, podemos ya volver a nuestro punto. La dificultad cognitiva es mayor en las decisiones morales no primarias (o sea, en las que se toman ante las mencionadas parábolas) que en aquellas que hemos llamado primarias, o sea, las que se toman directamente ante los intereses y necesidades de otros individuos. Pero ¿qué hay de la dificultad moral de la decisión?

\section{LA DECISIÓN MORAL ES FACILITADA EN LA PARÁBOLA}

En las parábolas el recurso de apelar a la coherencia cognitiva facilitaría la demandante decisión moral. Ciertamente, esta decisión sigue pareciéndole al sujeto tan dura después de oír la parábola como antes. Sin embargo, la parábola le habría urgido hacia ella. Esa facilitación tiene en nuestro grupo de parábolas un primer requisito, un primer gran aliado con el que cuenta el productor de la parábola. Para enfocarlo, conviene que volvamos a un punto que ya tocamos arriba: Es un hecho que a todos nos gusta evaluar y juzgar las acciones ajenas, y que lo hacemos de un modo automático y sin el menor esfuerzo. Intentemos ahora ver este punto con más detalle.

El castigo de injusticias por parte, no de la víctima, sino de una tercera persona no vinculada a la víctima —o sea, el llamado third-party (or altruistic) punishment- es una tendencia que ha sido recientemente estudiada y de la que parece que se puede ya afirmar que es exclusivamente humana. ${ }^{33}$ Por supuesto, como vimos arriba cuando citamos a

33 Parecen haber ganado la partida los argumentos de Marco F. G. SchmidT - Michael Tomasello, "How Chimpanzees Cooperate: If Dominance is Artificially Constrained", Proceedings of the National Academy of Sciences of the USA 113 (2016) E6728-E6729. Esos autores critican la postura de quienes admiten la presencia de esa conducta en los primates no humanos, como, por ejemplo, Malini SUCHAK et al."How Chimpanzees Cooperate in a Competitive World", Proceedings of the National Academy of Sciences of the USA 113 (2016) 10215-10220. 
Pedersen et al. ${ }^{34}$ esa tendencia deja muy frecuentemente de manifestarse: por ejemplo, no se cumple cuando la escena es observada sin conocer el contexto que sería necesario para su interpretación, o, cuando el observador, al encontrarse en medio de la realización de una conducta no automatizada, no le puede prestar la atención que de otro modo le habría prestado. Pero, en cambio, cuando al observador le han señalado la escena mediante una narración, esa tendencia al castigo altruista o, al menos, a la indignación que le precede, se hace siempre presente. Y eso es lo que a nosotros aquí nos interesa. Además de esa reacción ante las maldades que uno ha observado como mero espectador, hay que tener en cuenta también la admiración que se nos puede despertar ante el espectáculo de unas acciones ajenas. "Witnessing another's altruistic behavior elicits elevation, a discrete emotion that, in turn, leads to tangible increases in altruism." 35

¿Cuál pudo ser el origen de esa atención y esas reacciones a las acciones ajenas? Algunos trabajos ${ }^{36}$ han propuesto que serían causadas por la competición ${ }^{37}$ que en una sociedad como la humana, donde la cooperación es imprescindible, surgirá entre los individuos con vistas a conseguir ser elegidos para una interesante tarea conjunta. Se trataría de vigilar a nuestros competidores, y ofrecer nosotros un mayor altruismo si el listón del altruismo ha sido puesto muy alto por ellos, y rebajar, por el contrario, nuestros ofrecimientos si el listón ha bajado. ${ }^{38}$ Pero es posible que haya otras causas igualmente importantes, o quizá más. El chismorreo o gossip que tanto se invoca en los estudios de evolución del lenguaje y del cual se afirma que actúa como un verdadero pegamento para la formación del grupo - esa actividad conversacional omnipresentenecesita alimentarse con la observación de hechos. Y, dado que, como Dessalles puntualiza, "the selection of reportable events is based on

34 Cf. Pedersen - McAuliffe - Mccullough, "The Unresponsive Avenger", 514-544.

35 Simone Schnall - Jean Roper - Daniel M.T. Fessler, "Elevation Leads to Altruistic Behavior", Psychological Science 21 (2010) 315-320.

36 Cf. Daniel M. T. Fessler - Colin Holbrook, "Baumard et al.'s Moral Markets Lack Market Dynamics" Behavioral and Brain Sciences 36 (2012) 89-90.

37 Cf. Nicolas BAUMARD - Jean-Baptiste AndRÉ - Dan SPERBER, "A Mutualistic Approach to Morality: The Evolution of Fairness by Partner Choice", Behavioral and Brain Sciences 36 (2012) 59-122.

38 FESSLER -HolBrOOK, "Baumard et al.'s Moral Markets", 89: "When the supply of prospective cooperators is greater than the number of open slots in cooperative ventures, the prospective cooperators can be expected to advertise that they have lowered their expected wages by displaying a willingness to engage in more costly prosocial behavior. Conversely, when the supply of prospective cooperators is lower than the number of open slots in cooperative ventures, the prospective cooperators can be expected to display a reduced willingness to engage in costly prosociality." 
unexpectedness and emotion", ${ }^{39}$ la atención a las malas o buenas acciones que podamos observar se seguiría imparablemente, aunque esas acciones no hayan tenido que ver nada con nosotros.

Pero, más allá de esas posibles causas de su surgimiento en la evolución, volvamos a lo que importa: La tendencia a evaluar automáticamente las acciones ajenas está profundamente arraigada en nosotros. La indignación de David ante la narración de Natán o la admiración de todos nosotros hacia el buen samaritano surgen de modo imparable. Así, ya tenemos el primer requisito que es necesario para conseguir el efecto facilitador de la parábola sobre la decisión moral. Ese requisito es un magnífico aliado que nunca deja de presentarse y viene siempre cargado de motivación emocional hacia la bondad. ${ }^{40}$

Por supuesto, antes de que el sujeto tome su decisión moral, tendrán que intervenir la comparación de estructuras y la coherencia cognitiva. Pero aquel magnífico aliado, gracias a su carga emocional, puede facilitar la decisión final del receptor de la parábola. La clave estriba obviamente en lo que ya vimos arriba tras revisar la disputa entre el simulacionismo y la"teoría de teoría": Ante una situación lejana a nosotros nos es siempre más fácil dar una respuesta objetiva y racional. ${ }^{41}$ Aquí debemos puntualizar - por cierto, muy en línea con la actual tendencia a difuminar cada vez más la frontera entre cognición y emoción- que esa respuesta no pierde en absoluto su objetividad y racionalidad por incluir una carga

39 Jean-Louis, DesSALLES, "Spontaneous narrative behaviour in homo sapiens: how does it benefit to speakers?" Proceedings of the 7th Evolution of Language Conference - Barcelona (2018) 91-98: DOI: 10.1142/9789812776129_0012.

40 En relación con esto, nos surge siempre una pregunta cuando atendemos al Antiguo Testamento, y también a épocas mucho más recientes. Concretemos esa pregunta ante la persona de David. Mientras que él llegó a sentir de modo abrumador su culpabilidad en relación con Urías, o sea, con alguien de su entorno, nunca se cuestiona, en cambio, sus campañas guerreras, en las que aniquiló aldeas enteras (2 Sam $27,8-9)$. O sea, estamos ante el famoso asunto de las dos etapas de la moral: la de las relaciones diádicas dentro del grupo y la de las reglas de aplicación universal. Para entender (o digerir) todo esto, lo mejor quizá sea enfocar los más de 150.000 años de nuestra especie. Durante casi todo ese tiempo, la supervivencia de cada clan —o, más tarde, de cada tribu - estaba realmente en peligro a menos que lograra mostrarse más fuerte que los grupos vecinos.

41 Wenin, "David et l'histoire de Natan", 162: "Lorsqu'il s'agit d'amener un être à sa vérité cachée, la fiction fait donc preuve d'une efficacité redoutable. En effet, elle a le pouvoir d'assumer le réel sans lui être asservie, de sorte qu'elle peut le remodeler de façon à déchirer le voile des apparences, à traverser le refus ou l'incapacité de voir les choses en face, et à faire venir au jour cette vérité enfouie. D'autant plus que ce qui vaut pour David à l'intérieur du récit pourrait également valoir pour le lecteur de son histoire". 
emocional. En otras palabras, una carga emocional no tiene por qué ser necesariamente un"sesgo" de aquellos a los que Heal se refería.

\section{LA PARÁBOLA DEL HIJO PRÓDIGO, Y SUS RASGOS PECULIARES}

Miremos ahora a la parábola del Hijo Pródigo, y podremos señalar una vuelta de tuerca a la estrategia ya descrita. Esta parábola aparece precedida por las de la oveja perdida y la dracma perdida, y, aún antes por las siguientes líneas: "Se acercaban a Él todos los publicanos y publicanos para oírle, y los fariseos y escribas murmuraban, diciendo: "Este acoge a los pecadores y come con ellos»" (Lc 15,1-2). Las parábolas de la oveja y la dracma oponen a la acusación emitida por los fariseos la alegría que hay en el cielo por cada pecador que hace penitencia, y se paran ahí. Pero la del hijo pródigo añade más elementos.

El primero es una pintura detallada de las dificultades que llegó a sufrir. Esta pintura provoca en el receptor una reacción automática de altruismo respecto al personaje. El altruismo hacia los personajes de ficción se prolonga siempre en una actitud de alegría ante la prosperidad que les pueda venir. ${ }^{42}$ Pero Jesús, en esta parábola, está hablando ante todo a los fariseos, y sabe que estos frenarán su reacción de alegría. No importa que esa reacción sea automática: Una fuerte motivación en contra que esté justo entonces recién activada (recuérdese el contexto que precede a la parábola) logrará frenarla en seco. Así, acabar justo tras el recibimiento amoroso por parte del padre no habría logrado facilitar la decisión moral en esos destinatarios. En este caso, el aliado emocional que habitualmente la escena del recibimiento habría suscitado no ha podido hacerse presente. Por eso, añadiendo un segundo elemento, Jesús introduce las protestas del receptor de actitud farisea en la parábola. De esa forma este receptor no podrá sino identificarse con el hermano mayor y hacer suyas todas las quejas del personaje.

En las otras parábolas no aparece nada parecido. Nosotros hemos supuesto cuáles pudieron ser las protestas que David tendría la tentación de oponer a la afirmación final de Natán, o las que pueden asomar en el receptor de la parábola del Buen Samaritano. Pero en ninguno de esos casos, las protestas aparecen explícitas en el texto. En realidad, tenemos

42 Esto, por cierto, marca una abrupta diferencia entre el altruismo ante la ficción y el altruismo espontáneo que sentimos ante nuestros vecinos reales, el cual no aparece ante la prosperidad, sino solo ante el sufrimiento y necesidad de ayuda que hayamos detectado en ellos. Las causas de esta diferencia se tratan en el ya citado BEJARANO, "The Most Demanding Moral Capacity". 
aquí un recurso textual muy sofisticado. Por supuesto, desde que hubo lenguaje, tuvo que haber momentos en los que se sucederían mensajes de diferentes hablantes, cada uno con un punto de vista diferente. Asimismo, muchísimos textos literarios de la Antigüedad —y también, huelga decirlo, algunos filosóficos - incluían diálogos entre personajes muy diferentes. Sin embargo, lo que encontramos aquí es diferente de todo eso. Aquí tenemos un texto a la vez muy breve y completamente unitario que, no obstante, intenta conseguir que el receptor se identifique primero con un personaje $y$, a continuación, con otro personaje de ideas muy diferentes. Esta estrategia es compleja y poco frecuente. ${ }^{43}$

La introducción del hermano mayor contribuye de seguro a facilitar la decisión moral de los receptores fariseos. Pero, ¿cómo tiene lugar esa contribución? La respuesta del Padre a las protestas de su hijo mayor está en la misma línea de amor incondicional que ya se había visto en su acogida al pródigo. Así se intenta, por supuesto, anular la envidia que asoma en las protestas. Pero hay algo más. Al hermano mayor no se le ofrece sólo el amor y la alegre reconciliación con su padre, sino también el poder participar en la fiesta conjunta del padre con todos sus hijos. Lo de la fiesta conjunta es sin duda un elemento clave, que ha sido posibilitado por las dos"voces" que se han sucedido en el texto. Quizá podríamos decir que, dado que la acogida al hijo pródigo ya había dejado claro (incluso para los receptores que frenaran la reacción espontánea ante ella) que el padre nos comprende y nos ama a todos como si estuviera dentro de cada uno, ahora los que se identifiquen con el hermano mayor podrían ver en esa fiesta, primero, la satisfacción del anhelo que todos tenemos de ser de ese modo comprendidos y amados, y, segundo, la posibilidad de que ese amor desbordante que todos los hijos recibimos acabe saltando desde cada uno hacia los demás.

Pero, volviendo a nuestra propuesta, subrayemos ante todo que el receptor fariseo, para valorar la fiesta conjunta, tendrá que tomar la decisión, que para él sigue siendo muy dura, de aceptar la semejanza esencial,

43 En la parábola de los trabajadores de la hora undécima (Mt 20,1-16), el esquema argumental es ciertamente parecido. Pero en ella no hay en absoluto protagonismo para esos trabajadores y su golpe de buena suerte. Esa parábola no hace esfuerzo alguno para que nos identifiquemos con ellos. Aquí, frente a lo que sucede en la del hijo pródigo, la única"voz" que está presente es la de los trabajadores que aguantaron el peso del día y el calor. (Estoy utilizando la palabra "voz" en un sentido al estilo de Bachtin, y de su"verdadera polifonía de las voces". Mijaíl BajTín, Problemas de la poética de Dostoierski, México: FCE, 1986, p.15. Ver también p. 11:“El discurso del autor real, en el caso de que exista, es de un tipo fundamentalmente especial que no puede tener un mismo estatuto que el de los personajes. Precisamente es este discurso el que determina la última unidad de la obra y su última instancia de sentido."). 
en el fondo bien conocida por él, entre la situación de su hermano ante el padre - esa situación de culpa y súplica-y la situación en la que él mismo se halla, o, dicho de otro modo, tendrá que rechazar la tentación de zafarse de las demandas de la coherencia cognitiva. Podemos ya resumir tanto los rasgos distintivos de esta parábola como la presencia en ella del esquema que es común a todas las de su grupo. Su primera parte viene a ser una versión extendida y elaborada $-\mathrm{y}$, sobre todo, más centrada en la interioridad del pecador- del mensaje de las parábolas de la oveja o la moneda perdida. O sea, lo que podría ser un mensaje completo pasa aquí a ser la primera de las dos situaciones que hay que comparar: este es un rasgo distintivo. La segunda situación es, claro, la propia del destinatario (el típico fariseo, en este caso): en ello, aunque es verdad que aquí se le ha dado voz al destinatario, no hay demasiada novedad frente a las otras parábolas. Pero ambas situaciones consisten aquí en la relación de un individuo con el padre: este es otro rasgo distintivo de esta parábola. No obstante, a pesar de esas peculiaridades únicas, la decisión moral que puede suscitarse ante esta parábola es semejante a la que hemos de tomar ante las demás parábolas: ¿Acepto de verdad que las dos situaciones son esencialmente iguales? ¿Moldeo mi propia atención para que se dirija a esa igualdad esencial, y a las consiguientes demandas por parte de la coherencia cognitiva?

\section{SÍNTESIS Y COMENTARIO FINAL}

El resumen mínimo del artículo podría ser que esas parábolas emplean variados y bien escogidos recursos para intentar así facilitar la decisión moral de sus oyentes. Ahora podemos añadir algún comentario. De hecho, la misma estructura del resumen sugiere dos bastante diferentes.

Un primer punto que se podría comentar es el de la esmerada y bien planificada construcción de las parábolas. En ellas, inteligencia, cultura, astucia, trabajo, sentido de la oportunidad, todo eso, está funcionando al máximo. Así, las pequeñas sugerencias que ofrece este artículo se enmarcarían en un asunto siempre actual, a saber, el de que la Palabra de Dios se haya expresado en la dinámica y los recursos —en las entretelas, podríamos decir - de unas palabras humanas. Recordemos lo que Benedicto XVI llamó "el estilo divino": "Dios, en vez de arrollarnos con su poder, llama con suavidad a las puertas de nuestro corazón" ${ }^{44}$ Por eso prefiere servirse de lo que es la mejor especialidad de los seres humanos,

44 Joseph Ratzinger, Jesús de Nazaret. II: Desde la entrada en Jerusalén hasta su resurrección, Madrid, Encuentro, 2011, 321. 
a saber, la de comunicarnos unos con otros y llegar a captar la mente del hermano. O, como se lee en la Dei Verbum 13, “Dios, en su infinita condescendencia, ha usado nuestras palabras y experiencias" para poder así hacer con nosotros una alianza que sea — por decirlo de forma escandalosa- de igual a igual. ${ }^{45}$

Pero hay otro punto que también podríamos comentar. Las parábolas buscan facilitar la decisión moral de los oyentes. Ese intento de influir en las decisiones ajenas, que es patente no solo en las parábolas sino en cualquier educación moral, ha sido a veces denunciado como manipulación. Ahora, tras haber subrayado de modo explícito la eficiencia de los recursos empleados en las parábolas, sería quizá oportuno afrontar, por breve y desmañadamente que sea, ese clásico asunto.

¿Cómo llega la manipulación a conseguir que un proyecto resulte atrayente? Cualquier manipulación, no importa a qué nivel opere, lo consigue conectando ese proyecto a alguna meta previamente activa en el sujeto. Así, la atracción y la fuerza biológica de esa meta revisten el proyecto en cuestión y hacen deseable la opción por él. En cambio, como hemos comentado varias veces a lo largo del artículo, al oyente de las parábolas la exigente decisión moral le sigue pareciendo igual de dura y exigente cuando ha acabado de oír la parábola que antes de oírla. Para este sujeto no hay conexión con ninguna meta previa suya, no hay fuerza biológica alguna que lo lleve en volandas hacia la decisión en cuestión. Todo lo que la parábola ha despertado - la coherencia cognitiva y todos los demás afectos - lo orienta, sí, y le facilita la decisión moral, pero no lo empuja para que la tome. Por eso, ante las parábolas lo mismo que ante las decisiones morales primarias, el propio sujeto habrá de empujarse a sí mismo. Lo tendrá que hacer a base de repintar y reforzar en su propia atención el punto relevante, utilizando para ello el habla interna dirigida a sí mismo, o, dicho de otro modo, la intrapersonalización del enorme poder del lenguaje. ${ }^{46}$ Ese procedimiento ciertamente se da también en cualquier autocontrol complejo, aunque no sea moral. Pero, mientras que en el autocontrol no moral el punto que ha de ser repintado y reforzado es una meta del sujeto - lejana en el futuro, desde luego, pero con fuerza biológica-, en la decisión moral, en cambio, el punto que el sujeto ha de reforzar es solo un hecho que él ha percibido y que a él le consta que es verdadero - la semejanza entre las dos situaciones, en las parábolas, o la

45 Una hermosa exposición de este asunto puede encontrarse en Álvaro PEREIRADelgado, "Verdad, carne y salvación. Consideraciones a propósito del enigma teológico de la verdad bíblica", Isidorianum 51-52 (2017) 27-36.

46 Cf. Teresa Bejarano, Inner Speech, Self-control and True Moral Freedom (trabajo en proceso). 
semejanza entre las necesidades del prójimo y las suyas propias, en las decisiones morales primarias. En definitiva, la libertad —el pequeño núcleo de verdadera libertad-que nos corresponde a los seres humanos no es impedida por esas parábolas; sino que, justo al contrario, puede ser puesta en acción por ellas. 